\title{
Diagnoses of Patients with Severe Subjective Health Complaints in Scandinavia: A Cross Sectional Study
}

\author{
Silje Maeland, ${ }^{1,2}$ Erik L. Werner, ${ }^{3}$ Marianne Rosendal, ${ }^{4}$ Ingibjorg H. Jonsdottir, ${ }^{5}$ \\ Liv H. Magnussen, ${ }^{1,2,6}$ Holger Ursin, ${ }^{1}$ and Hege R. Eriksen ${ }^{1,7}$
}

${ }^{1}$ Uni Research, Uni Health, P.O Box 7810, 5020 Bergen, Norway

${ }^{2}$ Faculty of Health and Social Sciences, Bergen University College, 5020 Bergen, Norway

${ }^{3}$ Research Unit for General Practice, Uni Research, Uni Health, 5020 Bergen, Norway

${ }^{4}$ Research Unit for General Practice, Institute of Public Health, Aarhus University, 8000 Aarhus, Denmark

${ }^{5}$ Institute of Stress Medicine, Gothenburg 41319, Sweden

${ }^{6}$ Department of Public Health and Primary Health Care, University of Bergen, 5020 Bergen, Norway

${ }^{7}$ Department of Education and Public Health, University of Bergen, 5020 Bergen, Norway

Correspondence should be addressed to Silje Maeland, silje.maeland@uni.no

Received 27 August 2012; Accepted 12 September 2012

Academic Editors: A. R. Mawson, C. Murata, and A. Zaborskis

Copyright ( $) 2012$ Silje Maeland et al. This is an open access article distributed under the Creative Commons Attribution License, which permits unrestricted use, distribution, and reproduction in any medium, provided the original work is properly cited.

\begin{abstract}
Background. A diagnosis is the basis of medical action, the key to various social privileges and national sick leave statistics. The objectives of this study were to investigate which diagnoses general practitioners in Scandinavia give patients with severe subjective health complaints, and what kind of treatments they suggested. Methods. One hundred and twenty-six self-selected general practitioners in Scandinavia diagnosed nine patients, presented as video vignettes, in a cross-sectional study. The main outcome measures were primary, secondary, and tertiary diagnoses. Results. The nine patients got between 13 and 31 different primary diagnoses and a large variety of secondary and tertiary diagnoses. Fifty-eight percent of the general practitioners chose different primary and secondary diagnoses, indicating that they judged the patients to have multimorbid complaints. The most commonly recommended treatment was referral to a psychologist, a mix of psychological and physical treatments, or treatment by the general practitioner. Conclusion. Scandinavian general practitioners give a large variety of symptom diagnoses, mainly psychological and general and unspecified, to patients with severe subjective health complaints. Referral to a psychologist or a mix of psychological or physical treatments was most commonly suggested to treat the patients.
\end{abstract}

\section{Introduction}

Classification and medical coding of illness and disease capture snapshot views of a patient's health. A diagnosis is the basis of medical action and it is the key to various social privileges [1]. Simplified diagnostic taxonomies are used to classify illness and disease for epidemiological purposes. In European primary, care the predominant system for classification and coding is the International Classification of Primary Care, Second edition (ICPC-2) [2, 3]. A diagnosis is intended to give a precise name, description, and reason for a complaint, symptom, or disease. It is also expected to guide treatment, predict prognosis, and provide social acceptance of the complaints. In addition, it works as a key to social privileges in many European countries.
Patients with severe subjective health complaints (SHCs) [4] frequently seek help from their general practitioner (GP), and severe SHC is the main reason for long-term sick leave [5]. These complaints are also known as medically unexplained symptoms (MUSs), somatoform disorders, functional somatic syndrome, bodily distress syndrome, somatization disorder [6,7], or multisystem illness [8]. Despite having the same, or similar complaints, the preferred label varies substantially [4]. Comorbidity or multimorbidity is a core feature in these patients [9-12], and medical investigations, laboratory tests, and referral to specialist seldom result in objective findings $[4,13]$. The patient may still require medical assistance due to high burden of the complaints. The prevalence of severe SHC in primary care varies between $5 \%-39 \%[11,14-18]$. In Denmark, $15 \%$ of 
the population report that they are limited in their daily functioning due to such complaints [19].

Diagnosing patients with severe SHC may be a challenge, mainly due to the high number of complaints that these patients report [20] but also due to lack of reference standards for the diagnosis [21]. In addition, research has been sparse due to lack of adequate methodology and the clinical complexity of these complaints [21]. Furthermore, diagnoses and labels seem to change over time, depending on other trends in society [7]. Historically, these complaints have been presented under numerous different labels, for example, asthenia, hysteria, burnout, stress, yuppie flu, fibromyalgia, and so forth [4]. It is still debatable if this is one general condition or if it is different conditions with substantial overlap $[4,22]$. It has been argued that the similarities between conditions are due to cross-sensitization [23]. In a recent study [24], the authors argue for a bifactorial model, in accordance with a strong general factor [25], and the existence of specific symptom patterns or complaints. "The iceberg of subjective health complaints may have many tips, but is it still one iceberg?" [22]. Despite these challenges, governmental health programs use the single diagnosis a patient is indexed within national statistics, health care planning, workers' compensation carriers, and others. It is also used by private health insurance companies and forms the basis for epidemiological research in this field. For a patient to be entitled to sick leave in Scandinavia, a GP has to apply a diagnosis to the patient. Diagnostics is an important, complex, and interesting part of general practice, yet scarcely investigated [26]. The primary objective of this study was to investigate if different GPs apply the same, or closely related, primary diagnosis to the same patients with severe SHC. The secondary objective was to study what treatments the GPs suggested for these patients.

\section{Methods}

Nine video vignettes were presented to 126 self-selected GPs in Scandinavia (see Table 1 for demography). In each of the vignettes, a consultation between a patient with severe SHC (played by professional actors) and his/her GP was presented. Each video was about 5-20 min long. In the beginning of each video, the GP (played by a GP) presented the patient's medical history, previous medical investigations, and the clinical results from these investigations, including lab results. It was also stated that no further tests or medical investigations were necessary (see Table 2 for a presentation of the nine patients). The vignettes were based on real-life consultations in a Norwegian GP office. Patients with severe SHC were asked by the GP if the consultation could be filmed for research purposes. In total, 19 real consultations were filmed. A reference group constituting researchers and GPs selected nine consultations that gave a broad distribution of age, gender, and complaint or symptoms presented. This provided diverse opportunities to explore diagnostic practices. A questionnaire with demographic variables was answered by each participating GP. The GPs were asked to give each patient up to three diagnoses (primary, secondary,
TABLe 1: Demographic profile of the Scandinavian GPs $(N=126)$ participating in the study. Number $n$ and percent in each category.

\begin{tabular}{lccccc}
\hline & $\begin{array}{c}\text { Scandinavia } \\
N=126\end{array}$ & $\begin{array}{c}\text { Norway } \\
n=56\end{array}$ & $\begin{array}{c}\text { Sweden } \\
n=29\end{array}$ & $\begin{array}{c}\text { Denmark } \\
n=41\end{array}$ & $\begin{array}{c}P \\
\text { value* }\end{array}$ \\
\hline $\begin{array}{l}\text { Female } \\
\text { Age }\end{array}$ & $63(50)$ & $20(36)$ & $16(55)$ & $27(66)$ & .01 \\
$\quad \leq 40$ & $25(20)$ & $15(27)$ & $5(17)$ & $5(12)$ & .09 \\
$\quad 41-50$ & $46(37)$ & $21(37)$ & $6(21)$ & $19(46)$ & \\
$\quad \geq 51$ & $54(43)$ & $20(36)$ & $17(59)$ & $17(41)$ & \\
GP & & & & & .01 \\
$\begin{array}{l}\text { experience } \\
\quad \leq 10\end{array}$ & $53(42)$ & $21(37)$ & $10(34)$ & $22(54)$ & \\
$\quad 11-15$ & $25(20)$ & $12(21)$ & $4(14)$ & $9(22)$ & \\
$\quad \geq 16$ & $47(37)$ & $23(41)$ & $14(48)$ & $10(24)$ & \\
$\begin{array}{l}\text { GP } \\
\text { specialist }\end{array}$ & $102(81)$ & $36(64)$ & $26(90)$ & $40(98)$ & .00 \\
$\begin{array}{l}\text { Other } \\
\text { specialties }\end{array}$ & $16(13)$ & $5(9)$ & $11(38)$ & - & .00 \\
\hline * $P$ value $(P \leq .05)$ for between-country differences (ANOVA). &
\end{tabular}

${ }^{*} P$ value $(P \leq .05)$ for between-country differences (ANOVA).

and tertiary) using the ICPC-2 pager [27]. They were also asked to suggest treatments and referrals in their own words. We counted the number of different ICPC-2 diagnoses for each patient, presented as number of diagnoses. We also organized the primary, secondary, and tertiary diagnoses according to ICPC-2 chapters, and these are presented as frequency (\%) of diagnoses within each chapter. We investigated how often GPs acknowledged comorbidity or multimorbidity and computed the variable "multimorbidity" based on number (\%) of GPs that gave primary and secondary diagnoses from different ICPC-2 chapters. Treatments and referrals were also reported in number (\%) of GPs suggesting different treatments and referrals. This variable was based on GP answers written in free text and categorized by a research assistant and the first author.

The language in the vignettes was Norwegian with subtitles in Swedish and Danish. The languages in the participating countries are very similar, like different dialects, and understood across countries.

A convenience sampling method was used, and in Norway, 56 GPs participated, 20 women and 36 men, in a 15-hour free of charge course approved by the Norwegian Medical Association (giving 15 points accredited to the GPs Continued Medical Education (CME) score). Four courses were offered, two in Oslo, one in Bergen, and one in Tromso. In Sweden, 29 GPs participated, 16 women and 12 men (one missing on gender information). Advertisement to recruit them was issued in the national journal of the Swedish Medical Association and on the Institute of Stress Medicine website. Participating GPs were reimbursed 500 Euros to see the nine video vignettes and answer questionnaires at home, using a secure web-based system. In Denmark, 43 GPs participated, but two unsuccessfully submitted the questionnaires online, resulting in 41 available responses, 27 women and 14 men. GPs participating in CME groups in the region of Southern Denmark and Central Denmark region 
TABLE 2: Description of the nine patients presented in the video vignettes.

\begin{tabular}{|c|c|c|c|c|c|}
\hline Vignette & $\begin{array}{l}\text { Gender, } \\
\text { age }\end{array}$ & Demography & $\begin{array}{l}\text { 1st complaint mentioned in } \\
\text { consultation/principal } \\
\text { complaint }\end{array}$ & Secondary complaints & Self-assessment of disability \\
\hline 1 & 우 25 & $\begin{array}{l}\text { Single, no children. } \\
\text { Interrupted secondary } \\
\text { education. } \\
\text { Currently in rehabilitation } \\
\text { program. } \\
\text { Several short time jobs and } \\
\text { sick leave spells. }\end{array}$ & $\begin{array}{l}\text { General pain in the neck, } \\
\text { the back, and in arms. } \\
\text { Intense pain } 24 \text { hours per } \\
\text { day, } 7 \text { days a week. }\end{array}$ & $\begin{array}{l}\text { Respiratory complaints, no } \\
\text { objective findings of } \\
\text { asthma or other known } \\
\text { somatic disease. Anxiety } \\
\text { and depression periodically } \\
\text { treated with } \\
\text { antidepressants. }\end{array}$ & $\begin{array}{l}\text { Expresses hope to achieve } \\
\text { ability to work, but need } \\
\text { substantial improvement in } \\
\text { health conditions first. }\end{array}$ \\
\hline 2 & $\sigma^{7} 40$ & $\begin{array}{l}\text { Married, two children. } \\
\text { Working offshore on oil } \\
\text { platform as a mechanic- } \\
\text { two weeks on, four weeks } \\
\text { off work. } \\
\text { Several shorter periods of } \\
\text { sick leave and two long } \\
\text { spells (one year each). }\end{array}$ & Back and neck pain. & $\begin{array}{l}\text { Sleeping disturbances due } \\
\text { to pain. } \\
\text { Irritable bowel syndrome, } \\
\text { skin eczema. }\end{array}$ & $\begin{array}{l}\text { The work is physically hard } \\
\text { and provokes pain. } \\
\text { He does not see himself in } \\
\text { this job until retirement, } \\
\text { but the salary and long } \\
\text { periods off work make him } \\
\text { keeping the job. }\end{array}$ \\
\hline 3 & q 53 & $\begin{array}{l}\text { Housewife for } 20 \text { years with } \\
\text { five foster care children in } \\
\text { addition to two biological } \\
\text { children. The fostering } \\
\text { years has ended and her } \\
\text { income consequently also. } \\
\text { Bringing up foster children } \\
\text { have been challenging due } \\
\text { to narcotics and psychiatric } \\
\text { disorders in the foster } \\
\text { children. }\end{array}$ & $\begin{array}{l}\text { Generalized, widespread } \\
\text { nonspecific pain. }\end{array}$ & $\begin{array}{l}\text { Anxiety, noninsulin } \\
\text { dependent diabetes, } \\
\text { general fatigue, no energy } \\
\text { left. }\end{array}$ & $\begin{array}{l}\text { She has not had any } \\
\text { working experiences } \\
\text { outside home for nearly } 30 \\
\text { years. } \\
\text { She feels exhausted and } \\
\text { wants to be left alone with } \\
\text { no demands of working } \\
\text { activity or qualification for } \\
\text { work. }\end{array}$ \\
\hline
\end{tabular}

Married, unknown number of children.

$4 \quad 0^{7} 37$

Previously working offshore, but started as self-employed in construction.
No other complaints, but has read about CFS which he finds fitting his

General intense fatigue. problems.

Economically burdens due to poor benefit coverage as self-employed.

No work capacity.

Married, three children.

Works as formwork

carpenter.

No previous history of sick

leave.

A 12 year old daughter with He feels physically and serious behavioral

$5 \quad 0^{7} 42$ problems, she refuses to go to school, meets her parents with substantial aggression, runs away from home. The girl is enrolled in a behavioral training program with great demands of parents' involvement.

No information on marital status or children.

Working in a kindergarten. psychologically exhausted, afraid that he might collapse.

No energy left to deal with his daughter after work.
Previous 4-month sick leave for same complaints was followed by no symptoms for one and a half years.
He needs a time off to deal

No other complaints. with his family problems. The program is set for 3-4 months.
Periodically numbness,

staring like a toothache, followed by headache and a

sensation of anesthesia on the right side of the body; things slip out of her hand.

No other complaints.

Extensive medical

examination has not

proved any cause of the symptoms. 
TABle 2: Continued.

\begin{tabular}{|c|c|c|c|c|c|}
\hline Vignette & $\begin{array}{l}\text { Gender, } \\
\text { age }\end{array}$ & Demography & $\begin{array}{l}\text { 1st complaint mentioned in } \\
\text { consultation/principal } \\
\text { complaint }\end{array}$ & Secondary complaints & Self-assessment of disability \\
\hline 7 & 우 35 & $\begin{array}{l}\text { No information on marital } \\
\text { status or children. } \\
\text { Working as teacher in } \\
\text { primary school. } \\
\text { No previous sick leave } \\
\text { history, no previous } \\
\text { psychiatric or somatic } \\
\text { disorder. }\end{array}$ & $\begin{array}{l}\text { Feeling tired, weak, does } \\
\text { not get things done, } \\
\text { struggling, powerless, } \\
\text { sleeping disturbances. } \\
\text { Relates the symptoms to } \\
\text { work overload. }\end{array}$ & No other complaints. & $\begin{array}{l}\text { She feels she may need time } \\
\text { out from work. }\end{array}$ \\
\hline 8 & $0^{7} 36$ & $\begin{array}{l}\text { Married, two small } \\
\text { children. } \\
\text { Working as teacher at } \\
\text { comprehensive level. } \\
\text { Very active sports trainer, } \\
\text { coaches a 1st division } \\
\text { handball team. } \\
\text { No previous sick leave } \\
\text { history, no previous } \\
\text { psychiatric or somatic } \\
\text { disorder. } \\
\text { Worried about possible } \\
\text { serious illness despite } \\
\text { negative examinations so } \\
\text { far. } \\
\text { An affair a year ago bothers } \\
\text { him a lot. }\end{array}$ & $\begin{array}{l}\text { Pain started in the jaw } \\
\text { muscle, following in the } \\
\text { neck, head, and stomach. }\end{array}$ & $\begin{array}{l}\text { Sleeping disturbances, } \\
\text { frustrated, lack of energy, } \\
\text { withdrawal from social } \\
\text { events and friends, anxious. }\end{array}$ & $\begin{array}{l}\text { He wants to return to work } \\
\text { but not for the moment. }\end{array}$ \\
\hline 9 & $0^{7} 38$ & $\begin{array}{l}\text { Married, no children. } \\
\text { Works as a technician in an } \\
\text { event bureau, producing } \\
\text { big shows, theatres, and } \\
\text { films. } \\
\text { As the work is located in } \\
\text { another city } 270 \mathrm{~km} \text { away, } \\
\text { he commutes weekly. }\end{array}$ & $\begin{array}{l}\text { General tiredness of work } \\
\text { and commuting, low } \\
\text { energy. } \\
\text { According to his wife, he is } \\
\text { irritable and passive, even } \\
\text { aggressive towards his wife. }\end{array}$ & No other complaints. & $\begin{array}{l}\text { The wife makes the doctor } \\
\text { appointment as he himself } \\
\text { has left work three weeks } \\
\text { ago and made no contact } \\
\text { with his employer. }\end{array}$ \\
\hline
\end{tabular}

were reimbursed 363 Euros to see the nine videos and answer questionnaires at home, using a secure web-based system before participating in a two-hour CME meeting.

For subgroup analyses, we split the GPs into their respective countries. ANOVA was used to test betweencountry differences in demographic variables. To see if the difference in number of participating GPs in the three countries influenced the results, we used a bootstrapping technique generating thousand replicated data samples based on repeated random drawing of diagnoses [28]. We obtained variance estimates that showed that the number of GPs in each country did not influence the results. This standard statistical technique showed that the different number of GPs from each country did not influence the results. PASW Statistics 18 were used and $P<.05$ was set as limit for statistical significance.

\section{Results}

A variety of different diagnoses (ICPC-2) were given to each of the nine patients with severe SHC (Table 3). Psychological diagnoses $(\mathrm{P})$ were the most frequent primary diagnoses, followed by general and unspecified (A), and musculoskeletal (L) diagnoses. Diagnoses from ICPC-2 chapter, digestive (D), eye $(\mathrm{F})$, ear $(\mathrm{H})$, neurological $(\mathrm{N})$, respiratory $(\mathrm{R})$, skin (S), endocrine/metabolic and nutritional (T), Female Genital (X), and Social problems (Z) were also used as primary, secondary, or tertiary diagnoses (Table 4). The number of primary diagnoses was high, ranging from 13 different diagnoses (for patient 9) to 31 different diagnoses (for patient 6). The majority of diagnoses were symptom diagnoses (ICPC-2 A-Z 1-29). (Table 4).

Ninety-nine GPs (79\%) gave the patients two different diagnoses. Among these, 57 GPs (58\%) chose the secondary diagnosis from another ICPC-2 chapter than the primary diagnosis (see the variable "multimorbidity" in Table 4).

The Norwegian GPs gave the highest number $(n)$ of diagnoses for all nine patients, followed by the Danish and the Swedish GPs, respectively. The difference in number of diagnoses observed between the countries could not be explained by the difference in number of participating GPs. This was evident from the bootstrapping technique. For patients 1, 
TABLE 3: Chapters of the ICPC-2 and a list of primary diagnoses the nine patients were given by the 126 GPs.

A: General and unspecified

A01 pain general/multiple sites, A04 weakness/tiredness general, A05 feeling ill, A27 fear of other disease NOS, A29 general symptom/complaint other, A97 no disease

L: Musculoskeletal

L01 neck symptom/complaint, L02 back symptom/complaint, L03 low back symptom/complaint, L05 flank/axilla symptom/complaint, L07 jaw symptom/complaint, L08 shoulder symptom/complaint, L18 muscle pain, L19 muscle symptom/complaint NOS, L28 limited function/disability, L29 sympt/complt. musculoskeletal other, L83 neck syndrome, L84 back syndrome w/o radiating pain, L86 back syndrome with radiating pain, L91 osteoarthritis other, L98 acquired deformity of limb, L99 musculoskeletal disease other

$\mathrm{N}$ : Neurological

N01 headache, N03 pain face, N05 tingling fingers/feet/toes, N06 sensation disturbance other, N18 paralysis/weakness, N27 fear of neurological disease other, N28 limited function/disability (n), N29 neurological symptom/complt. other, N81 injury nervous system other, N86 multiple sclerosis, N89 migraine, N90 cluster headache, N95 tension headache, N99 neurological disease other

\section{P: Psychological}

P01 feeling anxious/nervous/tense, P02 acute stress reaction, P03 feeling depressed, P04 feeling/behaving irritable/angry, P15 chronic alcohol abuse, P22 child behaviour symptom/complaint, P23 adolescent behav. symptom/complt., P25 phase of life problem adult, P28 limited function disability (p), P29 psychological symptom/complt. other, P73 affective psychosis, P74 anxiety disorder/anxiety state, P75 somatization disorder, P76 depressive disorder, P78 neurasthenia/surmenage, P80 personality disorder, P82 posttraumatic stress disorder, P99 psychological disorders other

R: Respiratory

R08 breathing problem, R74 upper respiratory tract infection, R83 respiratory infection other, $\mathrm{R} 99$ respiratory disease other

T: Endocrine/metabolic and nutritional

T86 hypothyroidism/myxoedema

\section{Z: Social problems}

Z05 work problem, Z06 unemployment problem, Z08 social welfare problem, Z12 relationship problem with partner, Z13 partner's behaviour problem, Z16 relationship problem with child, Z18 illness problem with child, Z20 relationship prob. parent/family, Z21 behaviour problem parent/family, Z28 limited function/disability (z), Z29 social problem NOS

$3,4,6,8$, and 9, the majority of the Danish GPs gave P diagnoses, whereas the Norwegian and Swedish GPs tended to give diagnoses within a larger variety of ICPC-2 chapters.

Referring the patient to a psychologist for further assessment and treatment was most commonly suggested. A mix of different referrals or treatments or treating the patient in his or her own GP office was also suggested. Combining these treatments was also common. Five of the GPs also suggested either blood tests or further referral to X-rays, CT, or MRI for a few of the patients.
There were significant country differences between most of the demographic variables (Table 1).

Health insurance status meeting (a meeting between the health care provider, the patient, the employer, and a representative from the Swedish Social Insurance Agency), which should be offered to all patients during rehabilitation, was recommended by less than $20 \%$ of the Swedish GPs in the study.

Less than $30 \%$ of the Danish GPs recommended a referral of the patients to social services (health benefits, social rehabilitation, etc.) at the social insurance office in the municipality.

\section{Discussion}

There was a substantial variation in diagnoses given to patients with severe SHC among GPs in Scandinavia. Psychological and general and unspecified diagnoses were most frequently used as the primary diagnoses. Many GPs gave secondary and tertiary diagnoses from other ICPC-2 chapters than they had used for the primary diagnosis. The majority of the diagnoses were symptom diagnoses. Referral to a psychologist was the most frequently recommended treatment, but a mix of different treatments was also commonly suggested. Many of the GPs preferred treating the patients in their own general practice.

Our results show that the diversity in symptom diagnoses is even larger than the list of unspecific symptom diagnoses for patients with MUS, suggested by Rosendal et al. [29]. In the present study, disease diagnoses (ICPC-2 A-Z 7099) were also applied. The findings are in line with previous research describing the challenges these patients present to the GP due to the self-limiting, often unexplained, and relapsing nature of these complaints [21]. Our results indicate that when patients with severe SHC consult with a GP, one GP may classify the condition as a musculoskeletal problem, another as a psychological problem, and a third may classify it as a social problem. Subjective health complaints have been acknowledged for many years, although the labels used have varied over time and between disciplines $[4,22]$. Our findings may contribute to the discussion if this is one general condition or if the patients our GPs were evaluating represented different, distinct conditions $[4,22]$. The patients that were presented in the video vignettes may represent patients with a strong general factor, as suggested by Witthöft et al. [24] and Deary et al. [25]. Within other health care system, and with different medical training, we do not know how the GPs would label these patients. The current system, using the ICPC-2, encourages a single and reductionistic diagnostic practice with a dualistic split between somatic and psychological conditions. Lack of objective findings [30] and the multimorbidity $[9,12]$ may explain the diversity of diagnoses from different ICPC2 chapters. Many of the GPs seemed to acknowledge this multimorbidity by using primary and secondary diagnoses from different ICPC-2 chapters, and this may be more in line with the history and the current literature about these complaints $[4,6,7]$ than the political and health policy system acknowledges. 
TABLE 4: Primary, secondary, tertiary diagnoses and suggested treatments for nine patient with severe SHC.

\begin{tabular}{|c|c|c|c|c|c|c|c|c|c|}
\hline \multirow{2}{*}{ Variable $(\mathrm{SD})^{\mathrm{a}}$} & \multicolumn{9}{|c|}{ Patient } \\
\hline & 1 & 2 & 3 & 4 & 5 & 6 & 7 & 8 & 9 \\
\hline \multicolumn{10}{|l|}{ Number of different diagnoses, mean (SD) } \\
\hline Primary diagnoses & 21 & 29 & 24 & 25 & 19 & 31 & 13 & 20 & 13 \\
\hline Symptom diagnoses (\%) & 61 & 53 & 61 & 63 & 89 & 68 & 47 & 49 & 88 \\
\hline Secondary diagnoses & 33 & 36 & 25 & 19 & 21 & 25 & 11 & 26 & 17 \\
\hline Symptom diagnoses (\%) & 55 & 74 & 64 & 64 & 90 & 81 & 69 & 75 & 86 \\
\hline Tertiary diagnoses & 29 & 22 & 21 & 11 & 15 & 7 & 6 & 16 & 9 \\
\hline Symptom diagnoses (\%) & 59 & 72 & 62 & 86 & 75 & 60 & 90 & 89 & 100 \\
\hline \multicolumn{10}{|l|}{ ICPC-2 chapters \% (primary diagnoses) } \\
\hline General and unspecified (A) & 19 & 5 & 24 & 45 & 16 & 12 & 12 & 26 & 17 \\
\hline Musculoskeletal (L) & 35 & 60 & 9 & 5 & 2 & 8 & 0 & 2 & - \\
\hline Neurological (N) & - & - & - & 4 & - & 49 & 0 & - & - \\
\hline Psychological (P) & 40 & 18 & 58 & 31 & 64 & 23 & 84 & 68 & 63 \\
\hline Respiratory (R) & - & 6 & 1 & - & - & - & - & - & - \\
\hline Endocrine/metabolic and nutritional (T) & - & - & - & 1 & - & - & - & - & - \\
\hline Social $(Z)$ & 1 & 2 & 5 & 2 & 14 & 2 & 1 & 2 & 17 \\
\hline No diagnoses & 6 & 8 & 4 & 3 & 5 & 6 & 3 & 2 & 4 \\
\hline \multicolumn{10}{|l|}{ ICPC-2 chapters \% (secondary diagnoses) } \\
\hline General and unspecified (A) & 10 & 5 & 10 & 13 & 5 & 13 & 7 & 13 & 2 \\
\hline $\operatorname{Ear}(\mathrm{H})$ & - & - & - & - & - & 2 & - & - & - \\
\hline Digestive (D) & - & 3 & - & - & - & - & - & 1 & - \\
\hline Musculoskeletal (L) & 14 & 41 & 19 & 4 & 12 & 1 & - & 11 & 1 \\
\hline Neurological (N) & 3 & - & 1 & - & - & 21 & - & 2 & - \\
\hline Psychological (P) & 41 & 14 & 39 & 21 & 22 & 10 & 30 & 29 & 21 \\
\hline Respiratory (R) & 10 & 6 & - & - & - & - & - & - & - \\
\hline Skin $(S)$ & - & 3 & - & - & - & - & - & - & - \\
\hline Endocrine/metabolic and nutritional $(\mathrm{T})$ & - & - & 4 & - & - & - & - & - & - \\
\hline Social $(Z)$ & 1 & 3 & 5 & 2 & 16 & 1 & 3 & 5 & 11 \\
\hline No diagnoses & 21 & 26 & 23 & 60 & 45 & 53 & 60 & 40 & 65 \\
\hline \multicolumn{10}{|l|}{ ICPC-2 chapters \% (tertiary diagnoses) } \\
\hline General and unspecified (A) & 6 & 2 & 3 & 2 & 2 & 2 & 1 & 7 & - \\
\hline Digestive (D) & 1 & 5 & - & - & - & - & - & - & - \\
\hline Eye $(\mathrm{F})$ & - & 2 & - & - & - & - & - & - & - \\
\hline Musculoskeletal (L) & 5 & 6 & 7 & 4 & 9 & - & - & 9 & - \\
\hline Neurological $(\mathrm{N})$ & 2 & - & - & - & - & 4 & - & - & - \\
\hline Psychological (P) & 20 & 10 & 14 & 4 & 4 & 2 & 4 & 9 & 6 \\
\hline Respiratory (R) & 10 & 2 & - & - & - & - & - & - & - \\
\hline Skin $(S)$ & - & 7 & - & - & - & - & - & - & - \\
\hline Endocrine/metabolic and nutritional $(\mathrm{T})$ & - & - & 6 & 1 & - & - & - & - & - \\
\hline Female genital $(\mathrm{X})$ & - & - & 2 & - & - & - & - & - & - \\
\hline Social $(Z)$ & 1 & 1 & 5 & 1 & 1 & 1 & 3 & 3 & 4 \\
\hline No diagnoses & 57 & 64 & 64 & 89 & 84 & 92 & 92 & 72 & 90 \\
\hline \multicolumn{10}{|l|}{ Multimorbidity \% } \\
\hline Yes & 58 & 46 & 52 & 21 & 43 & 32 & 18 & 39 & 20 \\
\hline \multicolumn{10}{|l|}{ Treatments \% } \\
\hline Physiotherapist & 6 & 12 & 1 & 2 & 1 & 7 & 25 & 14 & - \\
\hline Psychologist & 24 & 11 & 27 & 22 & 12 & 11 & 34 & 48 & 14 \\
\hline GP & 6 & 10 & 5 & 9 & 15 & 6 & - & - & 25 \\
\hline Mixed & 27 & 18 & 26 & 23 & 7 & 19 & 11 & 14 & 4 \\
\hline
\end{tabular}


TABle 4: Continued.

\begin{tabular}{|c|c|c|c|c|c|c|c|c|c|}
\hline \multirow{2}{*}{ Variable $(\mathrm{SD})^{\mathrm{a}}$} & \multicolumn{9}{|c|}{ Patient } \\
\hline & 1 & 2 & 3 & 4 & 5 & 6 & 7 & 8 & 9 \\
\hline Other & 12 & 19 & 14 & 18 & 20 & 25 & 3 & 6 & 18 \\
\hline No treatment suggested & 25 & 31 & 27 & 27 & 45 & 32 & 26 & 19 & 38 \\
\hline
\end{tabular}

${ }^{a}$ Data are numbers $(n)$, mean $(\mathrm{SD})$, and \% of primary, secondary, and tertiary diagnoses for patient $1-9$. The multimorbidity variable is calculated based on the number of GPs who gave different ICPC-2 chapter for primary and secondary diagnoses. Treatments are based on the number of GPs $(N=126)$ suggesting the different categories for each patient.

The most common diagnosis selected in our material was within the psychological chapter. This has also been found in previous research [31]. This may indicate that GPs perceive patients with severe SHC to have psychological problems, when there are no objective findings or any evident somatic disease. Many of these patients do not want somatic interventions and investigations [32] but seek emotional support from their GP [33]. Despite that, many GPs provide symptomatic treatments to these patients, even though they do not believe there is any disease to treat [32]. The GPs in our study suggested referrals to treatment providers like psychologist, physiotherapist, or they suggested treating the patients themselves, or often a mix of these three.

Repeated and costly investigations have been proposed to have an iatrogenic effect on this kind of patients hindering return to work [7]. In the beginning of each video that was presented to the GPs, statements were made that no further medical investigations were called for, and few GPs in the present study suggested referrals for further investigations.

The diagnostic diversity is of great importance for epidemiological research and in health policy in this area since the diversity results in a skewed picture of the prevalence of illness and disease. The registration of a single, symptombased diagnosis lacks information on the vast multimorbidity. This will have consequences for health care planning. Funding of treatment and rehabilitation programs is to a large extent based on statistics showing single diagnoses for multimorbid, subjective health complaints. We argue that, in their present form, these statistics are invalid.

It is the diagnostic system itself that is inadequate for identifying this cluster of health complaints. There is no consensus as how to improve the systems. Several suggestions exist, including a multiaxial coding system [31] or a new category of mild-to-moderate unspecific complaints in the ICPC-2 system [29]. A new uniform diagnosis must acknowledge the multimorbidity as a key issue in these patients [20]. In the mean time, we suggest that GPs give thorough descriptions of the patients abilities and possible limitations and apply multiple diagnosis in their evaluations of the patients health, when applicable. This may contribute to a better understanding of how many and who suffer from multimorbidity. Acknowledging this may in turn improve care for this group of patients that have a high burden of disease and are costly for society in terms of treatment, care, sick leave, and disability.

Furthermore, there is no consensus on the best treatment approach for these patients. The theoretical models for why some patients suffer from severe SHC range from somatic causes, perception, illness behaviour, and predispositions [34]. A general psychobiological sensitisation comprises all these perspectives and may explain the multimorbidity, and the unspecificity of the complaints $[4,9,35]$. The multimorbidity has been illustrated in this study, and a biopsychosocial perspective, rather than a biomedical perspective, may result in better clinical management and treatment for these patients in the future.

\section{Strengths and Limitations}

Our primary objective was to investigate how patients with severe SHC are diagnosed by GPs in Denmark, Norway, and Sweden; three countries with similar cultural and medical insurance policies. We cannot generalize our findings to all patients in general practice, to all GPs in Scandinavia, or to other countries with different insurance and diagnostic systems. This is in part due to the low number of selfselected GPs, differences in recruitment procedures, and demographic variables. The video vignette method does not necessarily mirror real life clinical decisions, particularly since the GPs could not ask the patients questions. However, this method may be as close to real clinical decisions as we can get with standardized patients. Despite these limitations, we observed a large number of diagnoses for each patient, in all three countries, and we find it likely that similar results would be observed from other GPs in other countries as well. There may be some minor differences between the countries, but our data do not permit further analyses of these possible differences.

\section{Conclusions}

There are numerous ways of labelling the same patients with severe SHCs and none of the labels or diagnoses could be assessed as being wrong. This indicates that diagnostic practice depends on what the individual GP choose to focus on, or perceive to be the patients, main illness, disease, or problem at the time of the consultation. Many of the GPs in this study acknowledge that these patients have multimorbid complaints. However, this is not reflected in the primary diagnosis that forms the basis for sick leave eligibility assessments and is used in the national registers. This may have consequences for the patients because epidemiologic studies are likely to give a skewed or even wrong picture about the kind of health problems sick-listed individuals suffer from. In turn, this may result in health care planning 
and funding of treatment and research that are not in tune with what the patients are suffering from.

Despite the diagnostic diversity, the GPs seemed to agree more on where to refer or treat these patients, and the majority suggested psychological treatment or a mix of different treatments.

\section{Conflict of Interests}

The authors declare that they have no conflict of interests.

\section{Acknowledgments}

The authors thank all the participating GPs, Univisjon for filming and producing the video vignettes, Stein Atle Lie for help with the bootstrapping routine, and Silje R. Reme and Nina Konglevoll for technical assistance. The authors also thank Elin Arvidson for valuable help with data collection in Sweden and Martin Munk, Dorthe Würtz, Carsten O. Henriksen for running the continued medical education groups in Denmark. The Norwegian Social Science Data Services approved the study. The Regional Committee for Medical and Health Research Ethics, Western Norway (REC West) concluded that since the study did not include individual health information, approval was not necessary. This work was supported by the Research Council of Norway (Grant no. 187885/H20).

\section{References}

[1] L. S. King, Medical Thinking. A Historical Prefase, Princeton University Press, Princeton, NJ, USA, 1982.

[2] S. de Lusignan, C. Minmagh, J. Kennedy, M. Zeimet, H. Bommezijn, and J. Bryant, "A survey to identify the clinical coding and classification systems currently in use across Europe," Medinfo, vol. 10, no. 1, pp. 86-89, 2001.

[3] I. M. Okkes, M. Jamoulle, H. Lamberts, and N. Bentzen, "ICPC-2-E: the electronic version of ICPC-2. Differences from the printed version and the consequences," Family Practice, vol. 17, no. 2, pp. 101-107, 2000.

[4] H. R. Eriksen and H. Ursin, "Subjective health complaints, sensitization, and sustained cognitive activation (stress)," Journal of Psychosomatic Research, vol. 56, no. 4, pp. 445-448, 2004.

[5] G. Tellnes. G., "Days lost by sickness certification," Scandinavian Journal of Primary Health Care, vol. 7, no. 4, pp. 245-251, 1989.

[6] F. Creed, E. Guthrie, P. Fink et al., "Is there a better term than "Medically unexplained symptoms"?" Journal of Psychosomatic Research, vol. 68, no. 1, pp. 5-8, 2010.

[7] S. Wessely, C. Nimnuan, and M. Sharpe, "Functional somatic syndromes: one or many?" The Lancet, vol. 354, no. 9182, pp. 936-939, 1999.

[8] B. D. Naliboff, "Towards a nondualistic approach to multisystem illness," American Journal of Gastroenterology, vol. 102, no. 12, pp. 2777-2780, 2007.

[9] E. M. Hagen, E. Svensen, H. R. Eriksen, C. M. Ihlebæk, and H. Ursin, "Comorbid subjective health complaints in low back pain,” Spine, vol. 31, no. 13, pp. 1491-1495, 2006.
[10] B. Stubhaug, T. H. Tveito, H. R. Eriksen, and H. Ursin, "Neurasthenia, subjective health complaints and sensitization," Psychoneuroendocrinology, vol. 30, no. 10, pp. 10031009, 2005.

[11] T. Toft, P. Fink, E. Oernboel, K. Christensen, L. Frostholm, and F. Olesen, "Mental disorders in primary care: prevalence and co-morbidity among disorders. Results from the Functional Illness in Primary care (FIP) study," Psychological Medicine, vol. 35, no. 8, pp. 1175-1184, 2005.

[12] M. Von Korff, P. Crane, M. Lane et al., "Chronic spinal pain and physical-mental comorbidity in the United States: results from the national comorbidity survey replication," Pain, vol. 113, no. 3, pp. 331-339, 2005.

[13] G. Tellnes, K. O. B. Svendsen, D. Bruusgaard, and T. Bjerkedal, "Incidence of sickness certification. Proposal for use as a health status indicator," Scandinavian Journal of Primary Health Care, vol. 7, no. 2, pp. 111-117, 1989.

[14] A. Ring, C. F. Dowrick, G. M. Humphris, J. Davies, and P. Salmon, "The somatising effect of clinical consultation: what patients and doctors say and do not say when patients present medically unexplained physical symptoms," Social Science and Medicine, vol. 61, no. 7, pp. 1505-1515, 2005.

[15] R. Peveler, L. Kilkenny, and A. L. Kinmonth, "Medically unexplained physical symptoms in primary care: a comparison of self-report screening questionnaires and clinical opinion," Journal of Psychosomatic Research, vol. 42, no. 3, pp. 245-252, 1997.

[16] C. Burton, "Beyond somatisation: a review of the understanding and treatment of medically unexplained physical symptoms (MUPS)," British Journal of General Practice, vol. 53, no. 488, pp. 231-239, 2003.

[17] G. Hanel, P. Henningsen, W. Herzog et al., "Depression, anxiety, and somatoform disorders: vague or distinct categories in primary care? Results from a large cross-sectional study," Journal of Psychosomatic Research, vol. 67, no. 3, pp. 189-197, 2009.

[18] N. Steinbrecher, S. Koerber, D. Frieser, and W. Hiller, "The prevalence of medically unexplained symptoms in primary care," Psychosomatics, vol. 52, pp. 263-271, 2011.

[19] O. Ekholm, M. Kjøller, M. Davidsen, U. Hesse, L. Eriksen, and A. I. Christensen, "Health and disease in Denmark since 1987," in Sundhet og Sygelighet in Danmark \& Udviklimgen Siden, Copenhagen, Denmark, 2006.

[20] J. M. Aiarzaguena, G. Grandes, A. Salazar, I. Gaminde, and A. Sanchez, "The diagnostic challenges presented by patients with medically unexplained symptoms in general practice," Scandinavian Journal of Primary Health Care, vol. 26, no. 2, pp. 99-105, 2008.

[21] M. A. van Bokhoven, H. Koch, T. van der Weijden, and G. J. Dinant, "Special methodological challenges when studying the diagnosis of unexplained complaints in primary care," Journal of Clinical Epidemiology, vol. 61, no. 4, pp. 318-322, 2008.

[22] H. R. Eriksen and H. Ursin, "Sensitization and subjective health complaints," Scandinavian Journal of Psychology, vol. 43, no. 2, pp. 189-196, 2002.

[23] J. B. Overmier, "Sensitization, conditioning, and learning: can they help us understand somatization and disability?" Scandinavian Journal of Psychology, vol. 43, no. 2, pp. 105-112, 2002.

[24] M. Witthöft, W. Hiller, N. Loch, and F. Jasper, "The latent structure of medically unexplained symptoms and its relation to functional somatic syndromes," International Journal of Behavioral Medicine. In press. 
[25] V. Deary, T. Chalder, and M. Sharpe, "The cognitive behavioural model of medically unexplained symptoms: a theoretical and empirical review," Clinical Psychology Review, vol. 27, no. 7, pp. 781-797, 2007.

[26] C. Green and J. Holden, "Diagnostic uncertainty in general practice: a unique opportunity for research?” European Journal of General Practice, vol. 9, no. 1, pp. 13-15, 2003.

[27] Care NCfliHaS. ICPC-2 pager, http://www.kith.no/templates/ kith_WebPage__-_1633.aspx.

[28] B. Efron and R. J. Tibshirani, An Introduction to the Bootstrap, Chapman \& Hall/CRC, New York, NY ,USA, 1998.

[29] M. Rosendal, P. Fink, E. Falkoe, H. S. Hansen, and F. Olesen, "Improving the classification of medically unexplained symptoms in primary care," European Journal of Psychiatry, vol. 21, no. 1, pp. 25-36, 2007.

[30] S. Nilsen, E. L. Werner, S. Maeland, H. R. Eriksen, and L. H. Magnussen, "Considerations made by the general practitioner when dealing with sick-listing of patients suffering from subjective and composite health complaints," Scandinavian Journal of Primary Health Care, vol. 29, no. 1, pp. 7-12, 2011.

[31] R. Schaefert, G. Laux, C. Kaufmann et al., "Diagnosing somatisation disorder (P75) in routine general practice using the International Classification of Primary Care," Journal of Psychosomatic Research, vol. 69, no. 3, pp. 267-277, 2010.

[32] A. Ring, C. Dowrick, G. Humphris, and P. Salmon, "Do patients with unexplained physical symptoms pressurise general practitioners for somatic treatment? A qualitative study," British Medical Journal, vol. 328, no. 7447, pp. 1057-1060, 2004.

[33] P. Salmon, A. Ring, C. F. Dowrick, and G. M. Humphris, "What do general practice patients want when they present medically unexplained symptoms, and why do their doctors feel pressurized?" Journal of Psychosomatic Research, vol. 59, no. 4, pp. 255-262, 2005.

[34] J. Van Ravenzwaaij, T. C. Olde Hartman, H. van Ravesteijn, R. Eveleigh, E. van Rijswijk, and P. L. B. J. Lucassen, "Explanatory models of medically unexplained symptoms: a qualitative analysis of the literature," Mental Health in Family Medicine, vol. 7, no. 4, pp. 223-231, 2011.

[35] V. B. Wyller, H. R. Eriksen, and K. Malterud, "Can sustained arousal explain the Chronic Fatigue Syndrome?" Behavioral and Brain Functions, vol. 5, article 10, 2009. 


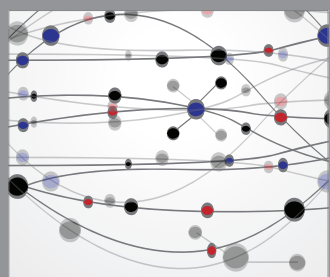

The Scientific World Journal
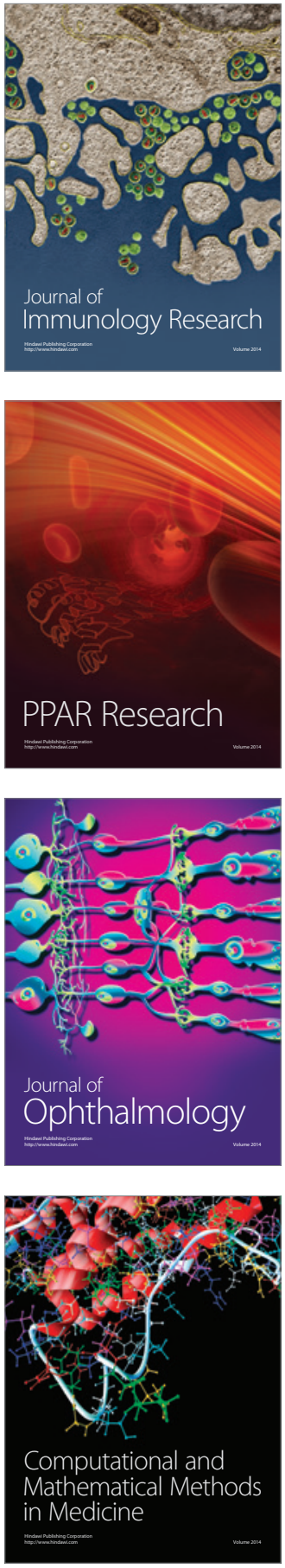

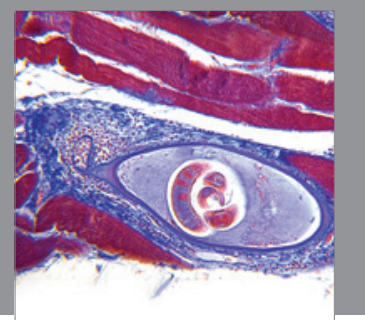

Gastroenterology

Research and Practice
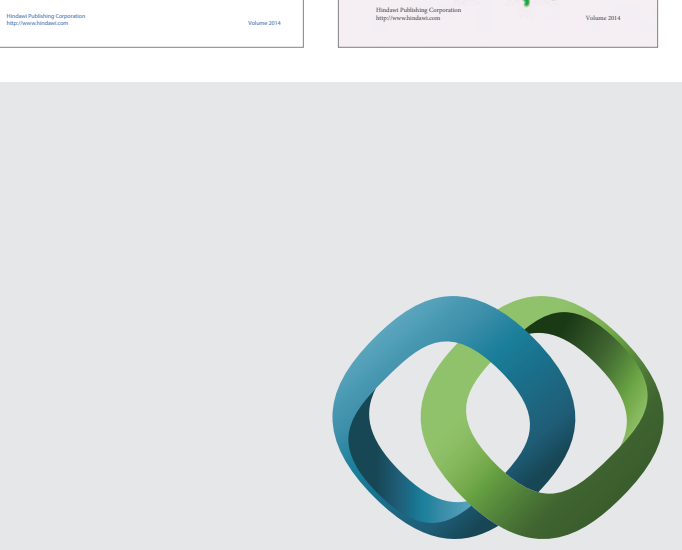

\section{Hindawi}

Submit your manuscripts at

http://www.hindawi.com
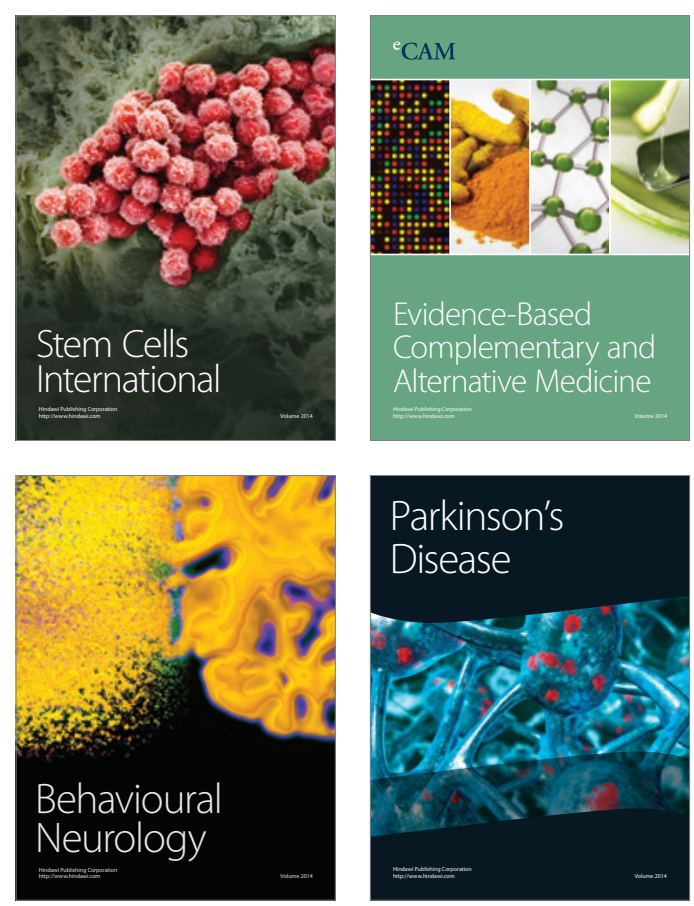

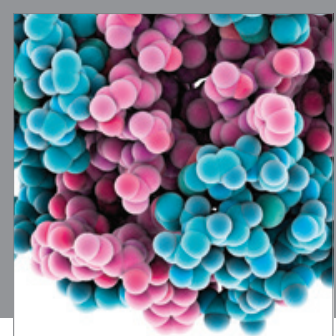

Journal of
Diabetes Research

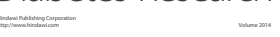

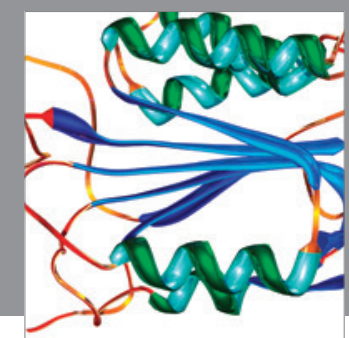

Disease Markers
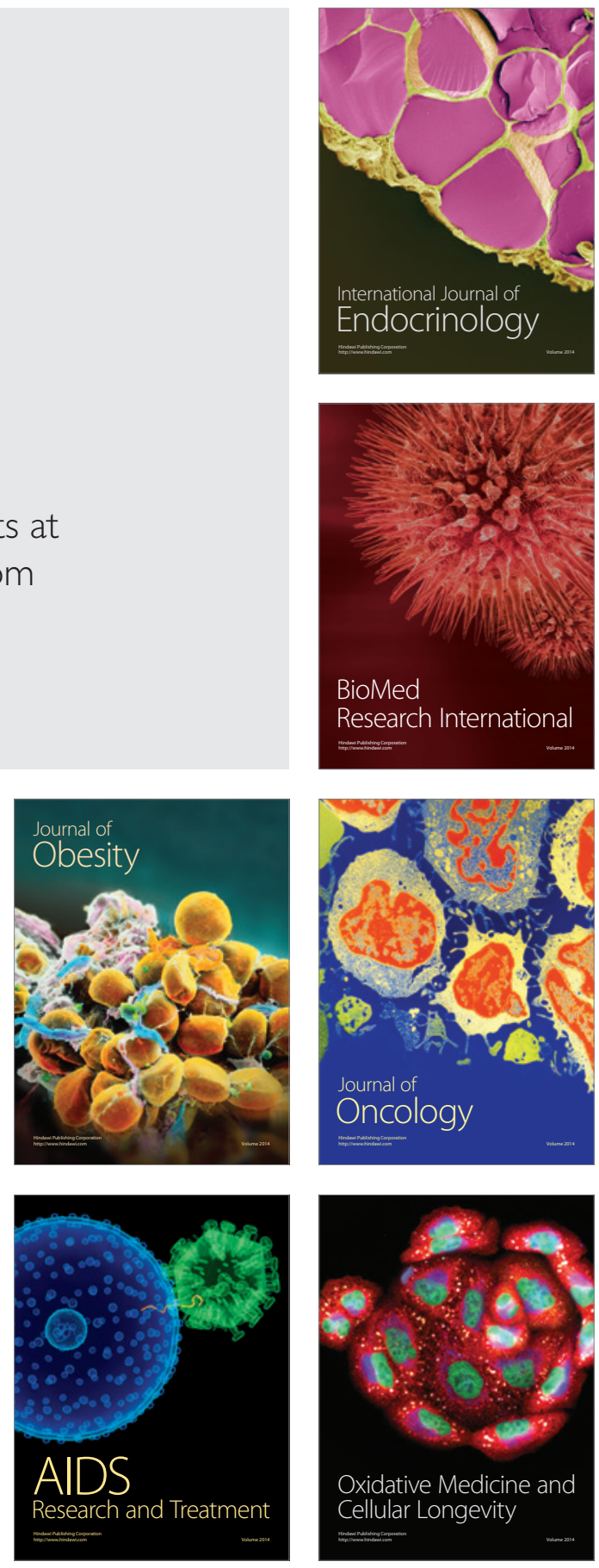